\title{
The Role of Nurses in Providing Health Education to The Family About The Children Enteral Nutrition
}

\author{
Diah Ayu Agustin \\ Bina Insan Nursing Academy Jakarta Indonesia \\ *Correspondence E-mail : diahayu@akperbinainsan.ac.id
}

\begin{abstract}
The role of nurses is very important in meeting with the nutritional needs of treated pediatric patients especially those receiving enteral nutrition. The role of nurses as educators is important to provide health education to families so that families can independently feed enteral nutrition to children especially after returning home. Purpose of this article explores various research journals related to health education to parents about child enteral nutrition. Method used is analysis of journal PICO. Population (Parents of pediatric patients who have enteral nutrition), Intervention (Health education to parents about child enteral nutrition). Comparation: Outcome (Increased parenting skills provide child enteral nutrition). The last 10 years of journal restrictions (2009-2018) coming from PubMed, NCBI, CINAHL, Medline and Proquest databases. Results of literature study show that nurse health education can improve parents' knowledge and skills in providing enteral nutrition to both treated and at home children. Conclusion: Nurses should educate enteral nutrition in parents of newly admitted pediatric care patients, accompanying parents delivering enteral nutrition and monitoring the child's response.
\end{abstract}

Keywords: role, nurse, education, enteral, nutrition, child

\section{Introduction}

Nutrition is an important component of children's health. Unfulfilled nutritional needs can lead to non-optimal growth and development, decreased immune system, and children are more susceptible to infection and can aggravate the illness, which can ultimately have an impact on mortality (Wilson, 2009). The fulfillment of nutritional needs is influenced by time, frequency, content, and quality of food consumed (Yi, 2018).

Children with prematurity or chronic disease may have special nutritional needs that cannot be met by their own oral intake, so it should be given enteral nutrition. Premature infants treated in Neonatal Intensive Care Unit (NICU) room require enteral nutrition to meet nutritional and fluid requirements. After being allowed to go home some premature babies are still receiving enteral nutrition for their survival (Toly, 2016).

In chronic hospitalized children, the provision of nutritional cannot meet the needs of children, so that alternative nutrition fulfillment is done in another way. One such alternative is enteral nutrition. Enteral nutrition is performed when the gastrointestinal tract can still be optimally utilized but the intake of calories through oral nutrition is insufficient (Yi, 2018).

Feeding enteral nutrition can be done by using feeding tube, the food pipe is inserted into the 
digestive system. Installation of this feeding tube can be done temporarily or in a long time.

Rosen et al. (2016) conducted a retrospective study in 2010-2013 in 87 pediatric patients, with an average age of 1.2 years. The most common diagnoses are congenital heart disease $(47 \%)$, metabolic disease $(17 \%)$, neurological disorders (10\%), liver disease $(9 \%)$, prematurity $(8 \%)$, and inflammatory bowel disease $(6 \%)$. At the latest follow-up, 44 $(50.6 \%)$ used full oral nutrition, $8(9.2 \%)$ were still using feeding tubes, 9 (10.3\%) had gastrostomy tubes, 9 (10.3\%) had died, and 17 $(19.5 \%)$ have either moved on or have not resumed the study. Average time to discontinuation of enteral nutrition was 4.8 months. Change in body mass index from hospital discharge to follow-up visit 6 to 12 weeks after discharge was statistically significant, from a mean (SD) of 13.78 (2.82) to 14.58 (2.1) $(P=0.02)$. Change in weight $z$ score was significant for neurologic impairment $(-1.35$ to $-0.04 ; P=0.03)$. Height $z$ score change was significant for prematurity $(-3.84$ to $-3.34 ; P=0.02)$. There was no significant change in height or weight $z$ scores for the other diagnoses. The conclusion of this study is enteral nutrition can help to improve short-term growth after hospital discharge in children with chronic illnesses.

In chronic conditions, the use of feeding tubes can last a long time until the client is treated at home, so the provision of further enteral nutrition depends heavily on the family at home (Evans et al., 2010).

Given the importance of enteral nutrition, proper counseling is needed in order to anticipate possible complications. The possible complications for enteral nutrition are mechanical, infectious, gastrointestinal and metabolic (Yi, 2018). The provision of nutrition in these patients is the responsibility of the nurse by involving the family as an application of child nursing philosophy that is Family Center Care (Dudley et al., 2015).

Parents with children who have enteral nutrition need to be involved in order to co-operate with the nurse in delivering the child's enteral nutrition. Therefore, the role of nurse as an educator is very important to equip parents skills for provide proper enteral nutrition.
Therefore, the child's nutritional needs are met. The role of this nurse is realized through health education activities.

The purpose of this article is to explore various research journals related to health education to parents about the provision of enteral nutrition of children. This article is expected to be useful as a reference for practical practice in providing appropriate enteral nutrition for pediatric patients and further research on child enteral nutrition.

\section{Methods}

This article uses the PICO journal analysis method (Population, Intervention, Comparation, Outcome), with details as follows:

$P$ : Parents of pediatric patients who have enteral nutrition

I: Health education to parents about child enteral nutrition

C : :

O: Increased parenting skills provide children's enteral nutrition

Problem question: whether health education can improve the parenting skills of providing enteral nutrition. Keywords: "enteral nutrition in children", "home enteral feeding", "parent's skill and knowledge in enteral feeding.

Journal search restrictions: The last 10 years from 2009-2018 through the PubMed online database, The National Center for Biotechnology Information (NCBI), Cumulative Index to Nursing and Allied Health Literature (CINAHL), Medline and Proquest.

\section{Results}

A study conducted in the United States (2009) explained that enteral nutrition can provide benefits that can support the healing process of disease, but can also cause complications. The complications that can be generated are as follows: gastrointestinal complications such as regurgitation, vomiting, aspiration, diarrhea, constipation, and jejunal necrosis. Mechanical complications such as catheter obstruction, catheter displacement, decubitus lesions. Metabolic complications such as fluid balance disorders and electrolytes and hyperglycemia. Provision of enteral nutrition should be done a 
good monitoring in order to be aware of possible complications that may occur. This journal is recommended by the American Society for Parenteral and Enteral Nutrition (ASPEN) based on the conclusions of health professionals in parenteral and enteral nutrition (Bankhead et al., 2009).

Evans Preston and his group (2010) conducted a study in England on 52 children with an average age of 7.5 years, who were treated at home using a feeding tube. This research uses observation method in parent / caregiver to ability of technique and skill in giving food through feeding tube. The results of this study reported that $48 \%$ of parents / caregivers are inaccurate in measuring foodstuffs, $31 \%$ prepare food without washing hands and $56 \%$ provide leftover food that is stored for too long.

A study conducted in Canada with a case report method that addresses cases of Naso Gastric Tube (NGT) position / location errors in the stomach in 5-month-old boys. This error can be avoided by checking the plaster marks on the tip of the nose. If the boundary marks have shifted from the original location, liquid food should not be given and the parents are requested to contact the nurse immediately for position repair (Johnstone et al., 2011).

Furthermore, another study was conducted at Birmingham in 2012. The study described that 32 children with an average age of 5.3 years, about the use of feeding tube more than 3 years in children who are treated at home. This study uses observation method and questionnaire on parents / carers to the knowledge and skills of enteral nutrition. The results reported that after 3 years there was a decrease in knowledge and skills, the accuracy of measuring foodstuff decreased from $36 \%$ to $11 \%$, the precision of feeding tube rinsing decreased from $56 \%$ to $44 \%$, controlling the feeding tube position before feeding decreased from $72 \%$ to $56 \%$, doing handwashing properly decreased from $38 \%$ to $25 \%$, and stored food correctly decreased from $87 \%$ to $38 \%$ (Evans et al., 2012).

A study in Spain was conducted for 10 years from January 1995 to December 2004 on 304 pediatric patients. This study using a retrospective design. The results of the study found that the cause of the children were given enteral nutrition in the hospital until home treatment was malignant disease 91 (29.93\%), indigestion 84 (27.63\%), neurological disorders $(23.03 \%)$, failure to thrive $70(9.21 \%)$, and other causes $31(10.2 \%)$. Pediatric patients who were given enteral nutrition to $218(71.7 \%)$ of home care from 304 children. The study also concluded that the level of parental knowledge is important for designing effective strategies for enteral nutrition at home (Ginner et al., 2012).

Research on other enteral nutrition was performed by Ginner and his colleagues (2013) using descriptive analysis designs of 952 children from 20 Spanish hospitals studied for 8 years (2003-2010), which obtained data of an increase in the number of children treated at home using feeding tubes as much as 25 -fold and the type of enteral feeding Most of them were nasogastric tube (54.7\%).

Tume et al. (2013) conducted a study of 108 hospital health workers in England and Ireland, $59 \%$ of whom were nurses. The study found that $96 \%$ of health workers had a feeding list through enteral and $85 \%$ of the officers said that the guidelines greatly helped to improve the effectiveness of nutrition.

Hannah \& John (2013) wrote an article using the results of several sources from the Cohrane Library and PubMed, CINHL, Ovid Medline. This journal describes the right size of NGT in children. The size of NGT in children is adjusted to the age of the child, namely: premature to neonates 4-5 French (Fr), infant and child size 5-8 Fr, Larger child until adolescence size 10-12 Fr.

A study in America explains that the involvement of families / parents in meeting the nutritional needs refers to the philosophy of nursing children that is family-centered care. Family-centered care is an innovative approach by planning, conducting and evaluating jointly between patients, families / parents and health workers, based on mutually beneficial relationships in health services. In principle, family-centered care has a basic concept of enabling and empowering families (Dudley et al., 2015).

Research conducted in the United States (2016) on a retrospective and descriptive 
method of researching technologically dependent neonates upon return. Research variables include demographic characteristics, length of stay in the hospital, and the type of medical technology used. Analysis of 22 neonates with 1 year postdischarge data was performed to identify the relationship between the utilization of health services.

The results explain that about $40 \%$ of neonates who depend on technology are between 23 and 26 weeks of pregnancy, with a birth weight of less than $1000 \mathrm{~g}$. The most commonly used technologies are supplemental oxygen (66\%) and feeding tube (46.5\%). The median and non-dependent neonatal hospital treatment rates were 108.6 and 25.7 days. Neonates who rely on female sex technology, with feeding tubes, or with earlier hospital stays are at greater risk for rehospitalization, the study also explains that parents need to receive health education for provide child enteral nutrition at home (Toly et al., 2016).

A study in Korea in 2018 using a review method describes feeding through NGT needs to be done correctly because it can be risky for infection complications, mechanical aspiration, gatrointestinal and metabolic. The first step before enteral nutrition is counseling. This will avoid complications of enteral nutrition (Yi, 2018).

The role of nurses is very important in providing nutrition to children who have feeding tube and providing health education about enteral nutrition to the family. The purpose of health education is the family has the knowledge and skills in delivering the child's enteral nutrition properly at home, so as to prevent unexpected events.

\section{Discussion}

The role of nurses in nursing care, among others, as nursing caregivers, advocates, consultants, educators, collaborators, innovators. The role of nurse as an educator is that nurses should be able to provide information and counseling to pediatric and family patients on all aspects of health and illness (Kyle \& Carman, 2013).

Child nurses should be able to ensure that communication with children and families is based on their age and developmental level. The nurse educates parents to provide information and ask questions (feedback) about the information provided, and evaluate the learning process.

Feeding tube is a polyvinyl or soft polyurethane tube / tube inserted into the gastrointestinal tract as a channel to supply nutrients to the body through the digestive system. One type of feeding tube is the Nasogastric tube (NGT). In NGT, pipe / hose is inserted through the nose, then into the esophagus and ends in the epigastrium (Coyne et al., 2010).

The size of NGT in children is adjusted for the age of the child, namely: premature to neonates size 4-5 Fr, infants and children 5-8 Fr size, Larger child until adolescence size 1012 Fr (Hannah \& John, 2013).

Procedure of Feeding Nutrition Through Feeding Tube (Bryce-Smith, 2011; Hockenberry \& Wilson, 2012).

1. Stage of Preparation

a. Describes procedures for children and parents

b. Wash hands thoroughly (use a 6 step technique according to World Health Organization / WHO)

c. Clean the dirt on the mouth, nose, and surrounding areas

d. Make sure the burette feeding is clean

e. Check the type of food and delivery time

f. Check the liquid food at warm conditions

g. Check the time of food to be given (hang times), should not be more than 4 hours at room temperature. If over time, the food should be replaced with a new one (Bankhead et al., 2009)

h. Check the location / position of feeding tube (NGT), by:

1) Check the plaster marks on the tip of the nose. If the boundary marks have been shifted out of place, liquid food should not be given and contact the medical team (Johnstone et al., 2011; Farrington et al., 2009).

2) Perform aspiration of stomach fluids. 
i. Gives a supine / italic position to the right on a child with a head higher than the body $\left(30-45^{\circ}\right)$.

\section{Implementation Phase}

a. Close the clamp / lock on the feeding burette

b. Enter the liquid food at the feeding burette according to the dose / amount

c. Flowing liquid food on a portion of a feeding burette tube (chamber)

d. Unlock the clamp / lock on the feeding burette flush the liquid food in the pipe / hose until no air and all the tubes / hoses filled with liquid food, cover the clamp again.

e. Hang a feeding burette at a maximum height of about $61 \mathrm{~cm}$ (2 feets) from the hull

f. Fold the tube / tube at the top of the feeding tube (NGT), open the feeding tube (NGT) cover and connect with the tip of the pipe on the feeding burette

g. Open the clamp / lock on the feeding tube burette, make sure the liquid food flows smoothly (observe the liquid food droplets).

h. Adjust the flow rate of liquid food to prevent vomiting and regurgitation, in infants no more than $5 \mathrm{ml} / 5-10$ minutes, the child should not exceed $10 \mathrm{ml} / \mathrm{min}$, with the average food will run out 30-60 minutes (Bankhead et al., 2009: Hockenberry \& Wilson, 2012).

i. After the liquid food runs out, rinse with water $3-30 \mathrm{ml}$, depending on the recommendation of the medical team and dietian (Bryce-Smith, 2011).

j. After rinse, close the clamp / lock on the feeding burette hose

k. Remove the NGT tip from the tip of the feeding tube burette

I. Close the cover at the top of the feeding tube (NGT)

$\mathrm{m}$. Maintain the position of the child with the head higher than the body $\left(30-45^{\circ}\right)$ for 30-60 minutes

$\mathrm{n}$. Wash feeding burette with warm water until clean, then dry.

\section{Evaluation Stage}

a. Record the time of giving, type, and amount of food given

b. Observe and note if there is vomiting and choking / regurgitation, the amount and color of the residue (> $25 \%$ of the previous amount of intake and brownish or green)

c. Check if there is a bloated and when the previous defecation.

d. Check/record feeding tube feeding time and feeding burette. Feeding tubes are usually replaced 5-7 days of use (Bankhead et al., 2009).

The role of nurse as nursing carer is very important in providing proper enteral nutrition. In addition, the role of nurse as an educator is also very important for parents or family can work with nurses in providing enteral nutrition for children according to the concept of family center care (Dudleyet al., 2015).

Health education on enteral nutrition is beneficial to improve the knowledge and skills of parents or families in providing child enteral nutrition through NGT. However, the nurse remains responsible for accompanying the parent to provide the enteral nutrition and monitoring the child's response to prevent infection, aspiration or other complications that are harmful to the child.

\section{Conclusion}

Enteral nutrition is given to pediatric patients whose calorie needs are insufficient when administered orally. Incorrect enteral nutrition can cause complications. Therefore, the role of nurse as nursing caregiver and educator is very important so that parents can cooperate in providing enteral nutrition.

Health education enhance the knowledge and skills of parents to provide enteral nutrition. The recommendation of this article is that nurses should provide health education on enteral nutrition to parents of newly admitted pediatric patients, accompanying parents to enteral nutrition and monitor the child's response so that the child's needs are met without complications of enteral nutrition. 


\section{References}

Bankhead, R., Boulatta, J., Brantley, S., Corkins, M., Guenter, P., \& Krenittsky, J. (2009). Enteral nutrition practice recommendation. Journal Parenteral Enteral Nutrition, 33,122-167.

Bryce-Smith, A., (2011). Guidelines on the management of enteral feeding $2^{\text {nd }}$ edn. Nasogasric tube placement \& nasogastric feeding. Dublin: Our Lady Children Hospital.

Coyne, I., Neill, F., Timmons, F. (2010). Clinical skills in childrens's nursing. Oxford: Oxford University press.

Dudley, Ackerman, Brown, \& Snow (2015). Patient and family centered care of children in the emergency department. Pediatrics, 135(1), 255-272. doi: 10.1542/peds. 20143424.

Evans, S., Preston, F., Daly, A., Neville, C., \& MacDonald, A. (2010). Accuracy of home enteral feeding preparation for children with inherited metabolic disorders. Journal of Human Nutrition and Dietetics, 24, 68-73.

Evans, S., Preston, F., Daly, A., Ashmore, C., Holden, C., \& MacDonald, A. (2012). Home enteral tube feeding in children with inherited metabolic disorders: a review of long term carer knowledge and technique. Journal of Human Nutrition and Dietetics, 25, 520-525.

Farrington, M., Cullen,L., Lang, S., \& Stewart, S. (2009). Nasogastric tube placement verification in pediatric and neonatal patients. Pediatric Nursing, 35(1), 17-24.

Gilbertson, H.R., Rogers, E.J., \& Ukoumunne, O.C. (2011). Determination of a practical $\mathrm{pH}$ cutoff level for reliable confirmation of nasogastric tube placement. Journal Parenteral Enteral Nutrition, 35(4), 540-544.

Giner, et al. (2013). Analysis on the Spanish national registry for pediatric home enteral nutrition (NEPAD): Implementation rates and observed trends during the past 8 years.
European Journal of Clinical Nutrition, 67, 318-323.

Hannah, E., \& John, R. M (2013). Everything the nurse practitioner should know about pediatric feeding tubes. Journal of The American Association of Nurse Practitioners, 25, 567-577.

Hockenberry, M. J., \& Wilson, D. (2009). Wong's essentials of pediatric nursing. $8^{\text {th }}$.ed.St Louis: Mosby Elsevier.

Hockenberry, M. J., \& Wilson, D. (2012). Wong's clinical manual of pediatric nursing, $8^{\text {th }}$ ed. St Louis: Mosby Elsevier.

Johnstone, J. C., Leung, J. S., \& Friedman, J. N. (2011). Nasogastric tube misadventures. Clinical Pediatrics, 50(10), 983-986.

Kyle \& Carman (2013). Essentials of pediatric nursing. Philadelphia: Lippincott William \& Wilkins.

Rosen et al. (2016). Home nasogastric feeds: feeding status and growth outcomes in a pediatric population. Journal Parenteral Enteral Nutrition, 40(3), 350-4.

Toly et al. (2016). Neonates and infants discharged home dependent on medical technology: Characteristics and outcomes. Advances Neonatal Care, 16 (5), 379-389.

Tume, Carter, \& Latten (2013). A UK and irish survey of enteral nutrition practices in pediatric intensive care units. British Journal of Nutrition, 109,1304-1322.

Wilson, S.L. (2009). Determinan of childhood morbidity and the role of malnutrition: Evidence from Indonesia. Dissertation Publishing Proquest. http://drum.lib.umd.edu/bitstream/1903/9964 /1/Wilson_umd_0117E_10930.pdf.

Retrieved on March, 192018.

Yi (2018). Enteral nutrition in pediatric patients. Pediatric Gastroenterology, Hepatology \& Nutrition, 21(1),12-19. 